\title{
Inhibition of the Replication of Clinical Drug-Resistant HIV-1 Strains by Small Molecule Integrase Inhibitors $\mathrm{M}_{5} 22$ and $\mathrm{M}_{5} 32$
}

Ibrahim S Abd-Elazem and Ru Chih C Huang

Department of Biology, The Johns Hopkins University, Baltimore, Maryland, 21218, USA

*Corresponding author: Ru Chih C Huang, Department of Biology,The Johns Hopkins University, Maryland, Baltimore, Maryland, 21218, USA, Tel: 410-516-5181; Fax: 410-516-5213; E-mail: rhuang@jhu.edu

Received date: October 28, 2014; Accepted date: November 19, 2014; Published date: November 25, 2014

Copyright: (C) 2014 Abd-Elazem I, et al. This is an open-access article distributed under the terms of the Creative Commons Attribution License, which permits unrestricted use, distribution, and reproduction in any medium, provided the original author and source are credited.

\begin{abstract}
Objective: Integrase (IN) is an enzyme essential for HIV-1 replication that has been a target of antiretroviral drug therapy. Since emerging HIV-1 variants have frequently become clinically resistant to antiretroviral agents, it is necessary to develop alternative IN inhibitors.
\end{abstract}

Methods: We tested IN inhibitors, $M_{5} 22$ and $M_{5} 32$, against clinically resistant HIV-1 strains to antiretroviral drugs (AZT, non-nucleoside reverse transcriptase inhibitors, IN drug raltegravir, protease inhibitors); wild-type and clinical isolate from HIV-infected patients. We performed disintegration studies to show the interaction of $M_{5} 22$ and $M_{5} 32$ with the catalytic core domain of HIV-1 IN and time-of-drug-addition experiments to determine the inhibition step of viral replication. We tested selection of HIV-1 with $M_{5} 22$ and $M_{5} 32$ to examine the emergence of new drug resistant virus. CD4 ${ }^{+}$cell count was calculated for several groups of cells infected with HIV, cells treated and non-treated with $M_{5} 22$ and $M_{5} 32$ to evaluate their protective effect.

Results: $M_{5} 22$ and $M_{5} 32$ inhibited the replication of HIV-1 strains (wild-type; drug-resistant; clinical isolate from infected patients; and laboratory strains) with high potency. These inhibitors interacted with the catalytic core domain of HIV-1 IN and blocked its activity, prevented viral integration. $M_{5} 22$ and $M_{5} 32$ interfered with the viral replication precisely at the integration step. HIV- 1 virus did not develop resistance to $M_{5} 22$ and $M_{5} 32$ for 20 viral passages (160 days). These IN inhibitors protected the infected cells from cytopathic effects and the CD4 ${ }^{+}$cell counts of these cells treated with $\mathrm{M}_{5} 22$ and $\mathrm{M}_{5} 32$ were found to be identical to those of the uninfected cells.

Conclusion: $\mathrm{M}_{5} 22$ and $\mathrm{M}_{5} 32$ are potent against clinical isolate from HIV-infected patients, wild-type and clinically resistant strains especially the relevant raltegravir-resistant virus. Development of $\mathrm{M}_{5} 22$ and $\mathrm{M}_{5} 32$ as new mutationinsensitive drugs aiming for the protection of $\mathrm{CD} 4^{+} \mathrm{T}$-cells during HIV infection in the clinical trials is in progress.

Keywords: HIV-1; Integrase inhibitors; Raltegravir; Drug resistance; $\mathrm{CD} 4^{+}$cell count

\section{Introduction}

Integrase (IN) is a clinically validated target for the treatment of human immunodeficiency virus infections [1]. Drug-induced mutations have been major obstacles in developing effective IN inhibitors for HIV-1 virus infection, which were reported with the diketo acid compounds [2]. The second most promising anti-HIV-1 IN developed was the raltegravir drug. In 2007, U.S. Food and Drug Administration (FDA) approved raltegravir (Isentress) as the first IN drug for treatment of HIV infected patients [3]. Raltegravir is a strand transfer inhibitor and HIV-1 strains resistant to this commercial drug were reported in 2008 [4,5]. Three primary mutations were responsible for raltegravir resistance. The two most frequent primary mutations were at positions Q148 $(\mathrm{Q} 148 \mathrm{~K} / \mathrm{R} / \mathrm{H})$ and N155 $(\mathrm{N} 155 \mathrm{H})$; whereas, a third primary mutation at $\mathrm{Y} 143(\mathrm{Y} 143 \mathrm{R} / \mathrm{C} / \mathrm{H})$ was less common $[1,6,7]$. A secondary mutation at position G140 (G140S) combined with the primary mutation $\mathrm{Q} 148 \mathrm{~K} / \mathrm{R} / \mathrm{H}$, significantly enhanced drug resistance in the virus. The development of drug resistance has become a major cause of failure among antiretroviral therapies for treating HIV-1 infection effectively [4,5]. FDA next approved two more integrase strand transfer inhibitors (INSTIs), dolutegravir (Tivicay) and elvitegravir (Vitekta). Dolutegravir, was the first second-generation of INSTI, and was approved in August 2013 for the treatment of antiretroviral-naïve and antiretroviral-experienced patients [8]. Subsequently on September 24,2014, FDA approved elvitegravir (Vitekta) as another INSTI used in combination with other antiretroviral drugs (HIV protease inhibitor) for the treatment of HIV-1 infection in treatment-experienced adults. Regretfully, research showed a F121Y mutation in HIV-1 again for these integrase strand transfer inhibitors, dolutegravir, elvitegravir and rategravir [9]. In addition to these catalytic site inhibitors, recent reports of several allosteric IN inhibitors, series of 2-(quinolin-3-yl) acetic acid derivatives (LEDGINs), established them as non-catalytic site inhibitors of HIV-1 IN. These compounds inhibited the interaction of LEDGF/p75-integrase. Studies again showed drug resistance in selection experiments with LEDGINs in cell culture [10-14]. Due to the failure of antiretroviral drugs and emergence of resistances to raltegravir, dolutegravir, elvitegravir, LEDGINs and other antiretroviral inhibitors, it is important to continue seeking IN inhibitors that are non-toxic to human cells and inhibit drug-resistant strains of HIV-1. Two such potent and selective HIV-1 IN inhibitors $\left(\mathrm{M}_{5} 22\right.$ and $\left.\mathrm{M}_{5} 32\right)$ were previously isolated from the natural plant 
product, Salvia miltiorrhiza and they did not show cytotoxicity at high concentrations [15].

HIV-1 IN is composed of three distinct domains, the N-terminal (residues 1-49), the catalytic core (residues 50-212), and the Cterminal (residues 213-288). The N-terminal domain is involved in enzyme multimerization, while the C-terminal domain, also called the DNA-binding domain, has strong but nonspecific DNA-binding activity [16]. HIV-1 IN, which mediates the integration of HIV-1 DNA and is required for stable production of progeny viruses [17], has no mammalian counterpart, making it an attractive target for antiviral drug design [18]. HIV-1 IN catalyzes two well-characterized reactions, terminal 3 '-end processing and strand transfer [16]. In addition, IN is capable of catalyzing the reverse reaction called disintegration [19]. This activity can be assayed in vitro to study the IN enzyme and its effects on viral integration, including the location of the enzyme's catalytic core domain, and provides a convenient tool for measuring drug effects on IN deletion mutants $\left(\mathrm{IN}^{50-212}\right)[19,20]$. We applied this method in the present study to determine whether $M_{5} 22$ and $M_{5} 32$ interact with the catalytic core domain.

In the current study, we further characterized the antiviral activities of these two IN inhibitors against wild-type virus; different resistant strains of HIV-1 to reverse transcriptase (RT), protease (PR), and integrase (IN) drugs especially raltegravir-resistant strain as well as clinical isolate from $\mathrm{HIV}$-infected patients. We performed disintegration experiments to determine the interaction of $\mathrm{M}_{5} 22$ and $\mathrm{M}_{5} 32$ with the catalytic core domain of HIV-1 IN. The protective values of $\mathrm{M}_{5} 22$ and $\mathrm{M}_{5} 32$ against HIV-1 were evaluated by comparing the $\mathrm{CD}^{+}$cell count in the drug treated infected cells and in the infected cells without treatments.

\section{Methods}

\section{Cells, viruses, and inhibitors}

We obtained H9, Sup-T1 cells and HIV-1 viruses (drug-resistant isolates and laboratory strains) from the AIDS Research and Reference Reagent Program, Division of AIDS, National Institute of Allergy and Infectious Diseases. In the present study, we used different drugresistant isolates. HIV-1 $1_{\text {RTMF }}$, is an AZT-resistant virus, HIV-1 $1_{\text {IIIB }}$ A17 variant, is highly resistant to inhibition by NNRTIs, and HIV-1 $1_{\mathrm{L} 10 \mathrm{R} /}$ M461/L63P/V82T/184V is resistant to structurally diverse PR inhibitors. The two laboratory strains used were HIV-1 $1_{\text {IIIB }}$ and HIV- $1_{\mathrm{MN}}$. In addition, we used two other HIV-1 strains, a resistant one to the IN drug raltegravir harboring double mutations of G140S and Q148H and a wild-type strain $\left(\mathrm{HIV}-1_{\mathrm{NL} 4.3}\right)$. Professor Zeger Debyser, Division of Molecular Medicine, Katholieke Universiteit Leuven, Flanders, Belgium generously provided these two strains. The drugs used were AZT (Retrovir), raltegravir (Isentress, Ral), and IN inhibitor (118D-24), which were obtained from the Division of AIDS (NIAID, NIH). Dextran sulfate 5000 (DS), was purchased from Sigma-Aldrich Company and inhibitors $\mathrm{M}_{5} 22$ (Lithospermic acid) and $\mathrm{M}_{5} 32$ (lithospermic acid B) used in the current study were purified from Salvia miltiorrhiza roots as previously described [15].

\section{Viral infection and drug treatment}

H9 and Sup-T1 cells were grown and maintained in RPMI 1640 medium supplemented with $10 \%$ Fetal Bovine Serum (FBS), 100 units/ml penicillin and $100 \mu \mathrm{g} / \mathrm{ml}$ streptomycin. We suspended $\mathrm{H} 9$ and Sup-T1 cells separately in culture medium at a concentration of
$1 \times 10^{5}$ cells $/ \mathrm{ml}$, and infected them with HIV for $2 \mathrm{~h}$ at a Multiplicity of Infection (MOI) of 0.1. After infection, we then washed the cells twice with PBS and once with the suspension culture medium. The cell suspension $(100 \mu \mathrm{l})$ was added to each well of a 96-well plate, containing each of the two inhibitors with the concentrations $[(0,1.25$, $2.5,5,10,20,40$, and $80 \mu \mathrm{g} / \mathrm{ml})$ that equal to $(2.3,4.6,9.3,18.6,37.1$, $74.2,148.4 \mu \mathrm{M}$ for $\mathrm{M}_{5} 22$ and 1.7, 3.4, 6.9, 13.9, 27.8, 55.6, 111.2 $\mu \mathrm{M}$ for $\left.\mathrm{M}_{5} 32\right)$ ]. After a four-day incubation, we sub-cultured the cells with fresh culture medium and appropriate concentrations of $\mathrm{M}_{5} 22$ and $\mathrm{M}_{5} 32$. We incubated the cells for an additional four days as previously described [15]. Eight days after infection, the antiviral activities of both inhibitors were determined using HIV-1 p24 antigen ELISA [21].

We collected uninfected human blood from a healthy donor and isolated Peripheral Blood Mononuclear Cells (PBMC) by FicollHypaque density gradient centrifugation. The cells were stimulated using $2 \mu \mathrm{g} / \mathrm{ml}$ of Phytohemagglutinin (PHA) and 32 units $/ \mathrm{ml}$ of human interleukin 2 (IL-2). We maintained cultures in RPMI 1640 medium supplemented with $15 \%$ fetal bovine serum (FBS). We infected cells $\left(5 \times 10^{6}\right.$ cells $\left./ \mathrm{ml}\right)$ with $\mathrm{HIV}-1_{\mathrm{RTMF}}$ or with clinical isolate from $\mathrm{HIV}$-infected patients at $37^{\circ} \mathrm{C}$ for $2 \mathrm{~h}$. After infection, we washed the cells twice with culture medium, suspended in fresh medium, plated in 24-well plates, and then we added increasing concentrations of $\mathrm{M}_{5} 22$ inhibitor. After a four-day incubation at $37^{\circ} \mathrm{C}, \mathrm{PBMC}$ cells were sub-cultured in fresh culture medium containing appropriate concentrations of $\mathrm{M}_{5} 22$ inhibitor and further incubated until day eight after infection. We used the HIV-1 p24 antigen ELISA assay to determine antiviral activities against drug-resistant virus and clinical isolate in PBMC cells. The $\mathrm{IC}_{50} \pm \mathrm{SD}$ indicated the antiviral activity, where we calculated standard deviation (SD) using KaleidaGraph version 4.0 (Synergy software).

\section{Disintegration assay}

We obtained a purified recombinant form of the full-length HIV-1 IN (amino acids ${ }^{1-288}$, wild-type) from the AIDS Research and Reference Reagent Program, Division of AIDS, National Institute of Allergy and Infectious Diseases. Dr. Robert Craigie (Laboratory of Molecular Biology, NIDDK, NIH, Bethesda, MD) generously provided the IN catalytic core domain (amino acids ${ }^{50-212}$, soluble IN Mutanttype, F185K). We performed the disintegration assay as previously described [20], with the following modifications. A Y-shaped oligonucleotide (i.e., a branched substrate in which the U5-end was integrated into the target DNA) mimicking the strand transfer (3'joining) product was used as a substrate. The HIV-1 disintegration substrate was composed of four oligonucleotides (MWG-Biotech, Inc.):

V1/T2 (5'-GACCCTTTTAGTCAGTGTGGAAAATCTCTAGCA GGCTGCAGGTCGAC-3'); T1 (5'-CAGCAACGCAAGCTTG-3'); T3 (5'GTCGACCTGCAGCCCAAGCTTGCGTTGCTG-3); and U5V2 (5'ACTGCTAGAGATTTTCCACACTGACTAAAAGGGTC-3'). The T1 strand was labelled at the 5 -end with $\left[\gamma^{-32} \mathrm{P}\right]$ ATP using T4 polynucleotide kinase as previously described [22]. The disintegration substrate (Y-oligomer) was prepared by annealing the labelled T1 strand with a 3-fold excess of the unlabelled T3, V1/T2, and U5V2 strands, incubated at $80^{\circ} \mathrm{C}$ for $3 \mathrm{~min}$, and then cooled slowly to room temperature. The IN reaction mixture, formulated as previously described [15], was mixed with increasing concentrations of $\mathrm{M}_{5} 22$ and $\mathrm{M}_{5} 32$ inhibitors $(0,0.1,1,10,20,30$ and $40 \mu \mathrm{g} / \mathrm{ml})$. We incubated the HIV-1 IN (300 nM) and the labelled substrate $(65 \mathrm{nM})$ with the reaction mixture for $60 \mathrm{~min}$ at $37^{\circ} \mathrm{C}$. An equal volume of stop solution 
(95\% formamide, $30 \mathrm{mM}$ EDTA, $0.1 \%$ xylene cyanol, $0.1 \%$ bromophenol blue) was added to each reaction and the samples were heated to $95^{\circ} \mathrm{C}$ for five minutes to denature the DNA. We fractionated the samples by electrophoresis on a $15 \%$ denaturing polyacrylamide gel. The substrate was end labelled on the target strand. Disintegration produced a longer DNA product, which generated the conversion of the labelled 16-mer substrate to a 30-nucleotide product. We visualized the product by autoradiography and performed quantitation by phosphorimaging. We then calculated the percent inhibition using the equation: $100 \mathrm{X}[1-(\mathrm{D}-\mathrm{C}) /(\mathrm{N}-\mathrm{C})]$, where $\mathrm{C}, \mathrm{N}$, and $\mathrm{D}$ were the fractions of DNA substrate converted to product for DNA alone (C), DNA plus IN (N), and IN plus drug (D). The $\mathrm{IC}_{50}$ values of both inhibitors were determined by plotting the log of drug concentrations versus percent inhibition and by determining the concentration that produced $50 \%$ inhibition.

\section{Time-of-drug-addition experiment}

We infected H9 cells with HIV-1 $1_{\text {RTMF }}$ at a MOI of 0.5 . After 1 -h incubation at $37^{\circ} \mathrm{C}$, then removed unadsorbed virus by washing three times with RPMI 1640 culture medium. DS, AZT, Ral, $\mathrm{M}_{5} 22$ and $\mathrm{M}_{5} 32$ were added to the cells at different time points after infection $(0,1,2$, $3,4,5,6,7,8,9,24$, and $25 \mathrm{~h}$ ) to test their effects on HIV replication, with the exception of DS, which was added before infection (before zero time). The presence of HIV-1 p24 antigen was determined for each inhibitor at $72 \mathrm{~h}$ after infection using HIV-1 p24 antigen ELISA assay. We added the reference inhibitors (DS, AZT and Ral) at a standardized concentration corresponding to 100 times their $\mathrm{IC}_{50}$ values and determined at an MOI of 0.01 as previously described [23].

\section{Search for emerging of HIV-1 mutants by the selection experiment in $\mathrm{H} 9$ cells}

We performed a selection experiment according to a previously described method [24]. We propagated HIV-1 $1_{\text {RTMF }}$ in H9 cells in the presence and absence of $M_{5} 22$ and $M_{5} 32$ inhibitors. The cells were infected at a MOI of 0.1 and treated with drug concentrations equal to the $50 \%$ inhibitory concentration $\left(\mathrm{IC}_{50}\right)$ of each inhibitor, as determined from the results displayed in Figures $2 \mathrm{~A}$ and $\mathrm{B}(4.6 \mu \mathrm{M}$ for $\mathrm{M}_{5} 22$ and $8.3 \mu \mathrm{M}$ for $\mathrm{M}_{5} 32$ ). Every three to four days, we sub-cultured the cells with appropriate inhibitor concentrations and then further incubated until day eight after infection. We performed passages by adding the culture supernatant to new $\mathrm{H} 9$ cells in the presence of an equal or higher concentration of the inhibitors. Since we observed no cytopathic effects, we sub-cultured the infected cells in the presence of the same concentrations of the inhibitors. The concentrations of inhibitors were gradually increased to 2-, 3-, and 4-times the $\mathrm{IC}_{50}$ values through the 20 passages of selection (160 days). The antiviral activities were determined in the presence and absence of both inhibitors by using HIV-1 p24 antigen ELISA [21].

\section{Cytosphere Assay}

We used the assay described by Coulter manual CD4 count kit that contains Coulter CD4 cyto-spheres reagent, inert latex spheres coated with murine monoclonal antibody to identify and manually enumerate by visible light microscopy the absolute count of $\mathrm{CD} 4^{+}$cells. We infected H9 cells with HIV-1 in the presence and absence of IN inhibitors $\left(\mathrm{M}_{5} 22\right.$ and $\left.\mathrm{M}_{5} 32\right)$. A comparison of $\mathrm{CD} 4^{+} \mathrm{T}$-cell counts were determined in three different groups, the first group of cells were infected with HIV-1, the second group of cells were infected and treated with IN inhibitors and the third group were uninfected cells. We performed quantitation of $\mathrm{CD}^{+}$cells according to the procedure of Coulter method (Beckman Coulter, Inc., USA) and as described before [25].

\section{Results}

\section{Inhibition of acute HIV-1 infection by integrase inhibitors}

To determine the potency of the IN inhibitors $M_{5} 22$ and $M_{5} 32$ (Figure 1), we used different strains of HIV and assayed their replication in H9, Sup-T1 cell lines, and PBMC in the presence and absence of these inhibitors. The antiviral activities of $M_{5} 22$ and $M_{5} 32$ against drug-resistant strains (HIV-1 $1_{\mathrm{RTMF}}, \mathrm{HIV}-1_{\mathrm{IIIB}} \mathrm{A} 17$ variant, HIV-1 $1_{\text {L10R/M461/L63P/V82T/184V }}$ ), laboratory strains (HIV-1 $1_{\text {IIIB }}$ and $\mathrm{HIV}-1_{\mathrm{MN}}$ ), and clinical isolate from HIV-infected patients are shown in Figure 2. $\mathrm{IC}_{50}$ values calculated from the dose response curves are shown in Figures 2A-E. The antiviral activity of $\mathrm{M}_{5} 22$ in infected H9 cells against drug-resistant strains was 2.0-11.1 $\mu \mathrm{M}$ while those infected with laboratory strains, was 16.7-20.4 $\mu \mathrm{M}$ (Figure $2 \mathrm{~A}$ and Table 1). We obtained similar results for $\mathrm{M}_{5} 32$, where the $\mathrm{IC}_{50}$ values were 1.3-8.3 $\mu \mathrm{M}$ for the drug-resistant strains, and 8.3-9.7 $\mu \mathrm{M}$ for laboratory strains (Figure 2B, Table 1). Experiments on Sup-T1 cells showed similar inhibition of replication for three different strains of HIV-1. The $\mathrm{IC}_{50}$ value of $\mathrm{M}_{5} 22$ against HIV-1 $1_{\mathrm{RTMF}}$ was $1.8 \pm 1.4 \mu \mathrm{M}$, whereas IC $_{50}$ for HIV-1 $1_{\text {IIIB }}$ was $2.7 \pm 1.4 \mu \mathrm{M}$ and HIV-1 $1_{\mathrm{MN}}$ was $2.7 \pm$ $1.1 \mu \mathrm{M}$ (Figure 2C). $\mathrm{M}_{5} 32$ inhibited the HIV-1 $1_{\mathrm{RTMF}}$ strain with an $\mathrm{IC}_{50}$ value of $4.8 \pm 0.9 \mu \mathrm{M}$, HIV-1 $1_{\text {IIIB }}$ with value of $3.4 \mu \mathrm{M} \pm 0.3$, and $\mathrm{HIV}-1_{\mathrm{MN}}$ with a value of $2.5 \mu \mathrm{M} \pm 0.3$ (Figure 2D). In addition, the $\mathrm{IC}_{50}$ values of $\mathrm{M}_{5} 22$ against the replication of HIV-1 $1_{\mathrm{RTMF}}$ and clinical isolate in PBMC were $3.5 \pm 0.9 \mu \mathrm{M}$ and $18.0 \pm 0.6 \mu \mathrm{M}$, respectively (Figure 2E). Both $\mathrm{M}_{5} 22$ and $\mathrm{M}_{5} 32$ inhibitors exhibited high efficacy against different HIV strains, including clinical isolate from HIVinfected patients and drug-resistant strains, in various cell types (H9, Sup-T1, and PBMC).

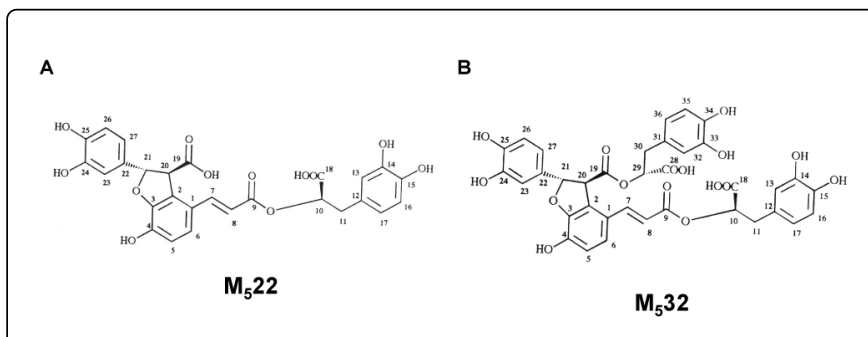

Figure 1: Chemical structure of $\mathrm{M}_{5} 22$ inhibitor (Lithospermic acid, Panel A) and $\mathrm{M}_{5} 32$ inhibitor (Lithospermic acid B, Panel B).

\section{Antiviral activity of IN inhibitors against raltegravir- resistant and wild-type strains}

H9 cells infected with raltegravir-resistant virus harboring double mutations of HIV-1 IN (G140S and Q148H) were treated with different concentrations of the IN inhibitors $\mathrm{M}_{5} 22$ and $\mathrm{M}_{5} 32$. We observed sensitivity of the raltegravir-resistant virus to these IN inhibitors. $M_{5} 22$ and $M_{5} 32$ showed high efficacy for inhibiting the replication of this mutant virus with $\mathrm{IC}_{50}$ values of $1.2 \mu \mathrm{M} \pm 0.4$ and $2.0 \pm 0.7 \mu \mathrm{M}$ respectively; whereas, the other two control integrase inhibitors, raltegravir (Ral) and IN inhibitor 118-D-24 showed only weak inhibition of the raltegravir-resistant virus (Figure $3 \mathrm{~A}$ ). The 
replication of wild-type strain $\left(\mathrm{HIV}-1_{\mathrm{NL} 4.3}\right)$ was also tested by both inhibitors and we found that this virus was strongly inhibited with $\mathrm{IC}_{50}$ values of $1.1 \mu \mathrm{M} \pm 0.4$ and $1.7 \pm 0.7 \mu \mathrm{M}$, respectively (Figure $3 \mathrm{~B}$ ). Results of replication inhibition for both raltegravir-resistant and wildtype viruses by $\mathrm{M}_{5} 22$ and $\mathrm{M}_{5} 32$ are similar to each other.
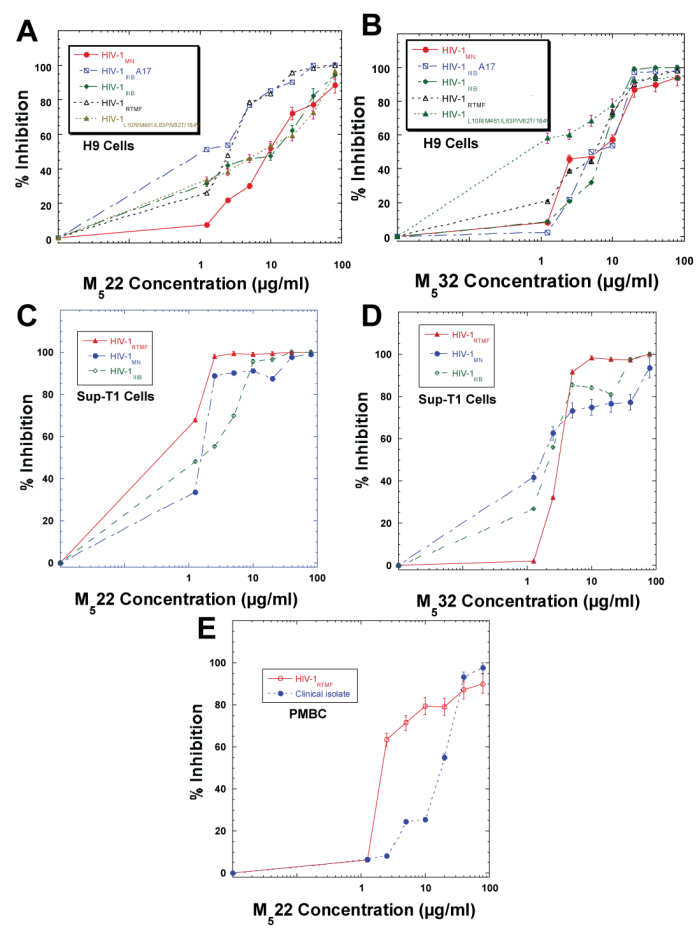

Figure 2: Effect of $\mathrm{M}_{5} 22$ and $\mathrm{M}_{5} 32$ inhibitors on the replication of drug-resistant strains, laboratory strains, and clinical isolate of HIV-1 in H9, Sup-T1, and PBMC cells. Three drug-resistant and two laboratory strains of HIV-1 were treated with increasing concentrations of $\mathrm{M}_{5} 22$ (Panel A) and $\mathrm{M}_{5} 32$ (Panel B) in $\mathrm{H} 9$ cells. Sup-T1 cells were infected with three strains of HIV-1 (drugresistant and laboratory strains), and these cells were treated with $\mathrm{M}_{5} 22$ (Panel C) and $\mathrm{M}_{5} 32$ (Panel D). PBMC were infected with drug-resistant and clinical isolate from HIV-infected patients and tested with $\mathrm{M}_{5} 22$ inhibitor (Panel E). The drug-resistant strains are HIV-1 $1_{\text {RTMF }}$ (AZT-resistant), HIV-1 IIIB A17 variant (Highly resistant to NNRTI), and HIV-1 1 L10R/M461/L63P/V82T/184V (Resistant to structurally diverse PR inhibitors), and the laboratory strains are HIV-1 $1_{\text {IIIB }}$ and HIV-1 $1_{\mathrm{MN}}$. Viral replication in the absence and presence of different drug concentrations and the $\mathrm{IC}_{50}$ values were determined from the dose response curve. The results obtained from the means and standard deviations from three independent experiments performed in duplicate.

\section{Interaction of $M_{5} 22$ and $M_{5} 32$ with $H I V-1$ Integrase}

The effects of both inhibitors were tested against the catalytic core domain ( $\mathrm{IN}^{50-212}$, mutant-type) as well as the full-length enzyme (IN ${ }^{1-288}$, wild-type) using the disintegration assay to determine whether $M_{5} 22$ and $M_{5} 32$ are able to block HIV-1 IN activity. $M_{5} 22$ inhibited the disintegration activity catalyzed by the catalytic core $\left(\mathrm{IN}^{50-212}\right)$ with an $\mathrm{IC}_{50}$ value of $4.0 \mu \mathrm{M}$ as illustrated in Figures $4 \mathrm{~A}$ and $4 \mathrm{C}$, and inhibited the full-length enzyme $\left(\mathrm{IN}^{1-288}\right)$ with an $\mathrm{IC}_{50}$ value of $3.3 \mu \mathrm{M}$ (Figures $4 \mathrm{~B}$ and $4 \mathrm{C}$ ). Similarly, $\mathrm{M}_{5} 32$ inhibited the activity of the catalytic core domain ( $\mathrm{IN}^{50-212}$ ) with an $\mathrm{IC}_{50}$ value of $6.2 \mu \mathrm{M}$ (Figures $4 \mathrm{D}$ and $4 \mathrm{~F}$ ), and the full-length $\mathrm{IN}\left(\mathrm{IN}^{1-288}\right)$ with an $\mathrm{IC}_{50}$ value of $5.8 \mu \mathrm{M}$ (Figures $4 \mathrm{E}$ and $4 \mathrm{~F}$ ). Overall, these results indicated that both $\mathrm{M}_{5} 22$ and $\mathrm{M}_{5} 32$ inhibited the activity of $\mathrm{IN}^{50-212}$, demonstrating that the integrase catalytic core region is the binding site for both inhibitors. The interaction between the inhibitors and the binding site is responsible for prevention of viral integration and inhibition of HIV-1 IN.

\begin{tabular}{|c|c|c|}
\hline \multirow[t]{2}{*}{ Virus strains } & \multicolumn{2}{|c|}{ Inhibitory concentration $\left(\mathrm{IC}_{50 \mathrm{a}}\right)$} \\
\hline & $M_{5} 22$ & $M_{5} 32$ \\
\hline \multicolumn{3}{|l|}{ Drug-Resistant Strains } \\
\hline HIV-1 $1_{\text {RTMF }}$ & $4.6 \pm 1.4$ & $8.3 \pm 1.2$ \\
\hline HIV-1 IIIB $_{\text {A }}$ A17 Variant & $2.0 \pm 1.3$ & $6.9 \pm 1.5$ \\
\hline HIV-1 L10R/M461/L63P/N82T/184V & $11.1 \pm 1.3$ & $1.3 \pm 0.7$ \\
\hline \multicolumn{3}{|l|}{ Laboratory Strains } \\
\hline HIV-1 ${ }_{\text {IIIB }}$ & $20.4 \pm 1.5$ & $9.7 \pm 1.4$ \\
\hline $\mathrm{HIV}-1_{\mathrm{MN}}$ & $16.7 \pm 1.1$ & $8.3 \pm 1.1$ \\
\hline
\end{tabular}

Table 1: Antiviral activities of $\mathrm{M}_{5} 22$ and $\mathrm{M}_{5} 32$ against drug-resistant, laboratory strains of HIV-1 in H9 cells. anti-HIV activity ( $\left.\mathrm{IC}_{50}\right), 50 \%$ inhibitory concentration or concentration of each inhibitor required to inhibit viral replication by $50 \%$ and calculated as $(\mu \mathrm{M}) \pm \mathrm{SD}$. Results were obtained from three independent experiments performed in duplicate.
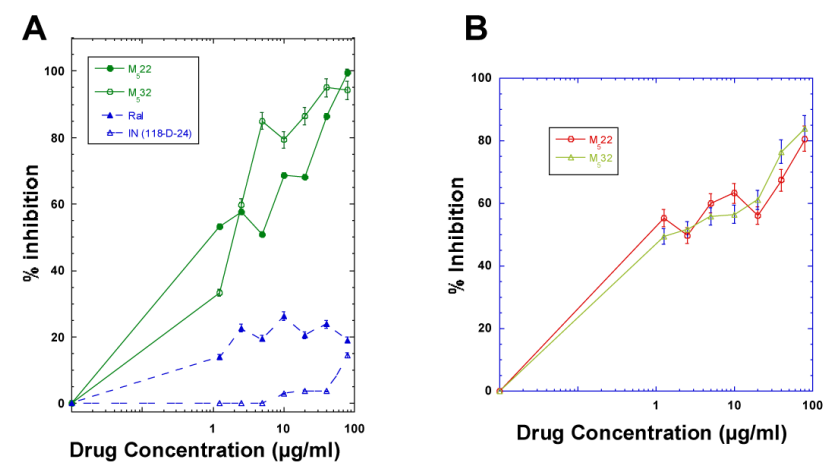

Figure 3: Inhibition of the replication of raltegravir-resistant and wild-type strains in $\mathrm{H} 9$ cells by $\mathrm{M}_{5} 22$ and $\mathrm{M}_{5} 32$ inhibitors. Cells were infected with raltegravir-resistant virus that contains the integrase mutations G140S and Q148H. The infected cells were treated with increasing concentrations of $\mathrm{M}_{5} 22$ and $\mathrm{M}_{5} 32$ and two controls [raltegravir drug and the IN inhibitor (118-D-24)] were included to be compared with our IN inhibitors (Panel A). Antiviral activities of both $M_{5} 22$ and $M_{5} 32$ against wild-type virus $\left(\mathrm{HIV}-1_{\mathrm{NL} 4.3}\right)$ were also tested (Panel B). Viral replication in the absence and presence of different drug concentrations and the $\mathrm{IC}_{50}$ values were determined from the dose response curve. The data obtained from the means of three independent experiments performed in duplicate and standard deviations were calculated. 

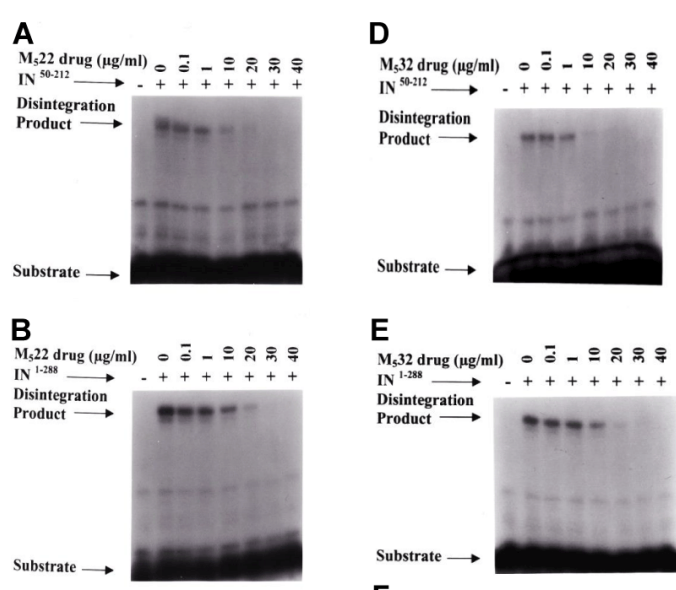

C
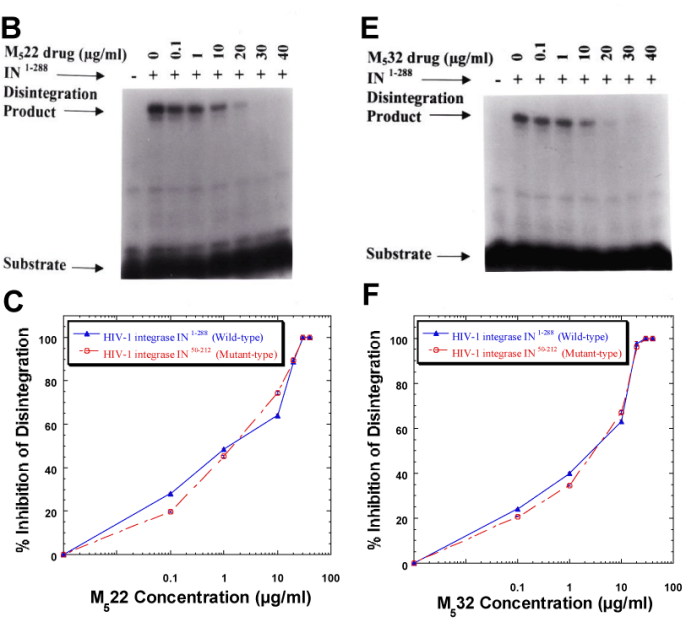

Figure 4: Inhibition of disintegration activity of catalytic core domain and full-length HIV-1 integrase by $\mathrm{M}_{5} 22$ and $\mathrm{M}_{5} 32$. The disintegration assay measured the conversion by HIV-1 IN of the radiolabeled 16-base oligonucleotide of the $\mathrm{Y}$-shaped substrate (see Methods) to a 30-base disintegration product. Increasing concentrations $(0,0.1,1,10,20,30$, and $40 \mu \mathrm{g} / \mathrm{ml})$ of $\mathrm{M}_{5} 22$ (Panels $\mathrm{A}$ and $\mathrm{B}$ ) or $\mathrm{M}_{5} 32$ (Panels D and $\mathrm{E}$ ) were added to disintegration assay reactions catalyzed by either the catalytic core domain $\left(\mathrm{IN}^{50-212}\right)$ or full-length HIV-1 integrase $\left(\mathrm{IN}^{1-288}\right)$. A graphic representation of the data for the disintegration assays (Panels A, B, $\mathrm{D}$, and E) as quantitated by phosphorimaging was presented, showing a dose-response inhibition of disintegration activity by $\mathrm{M}_{5} 22$ (Panel C) and $\mathrm{M}_{5} 32$ (Panel $\mathrm{F}$ ) for the full-length HIV-1 integrase (Wild-type) and its catalytic core domain (Mutant-type).

\section{Time of intervention on HIV replication cycle}

To investigate which step of the replication cycle was inhibited by $\mathrm{M}_{5} 22$ and $\mathrm{M}_{5} 32$, we performed a time-of-drug-addition experiment. In addition, we also evaluated when these IN inhibitors were needed in the viral replication cycle and for examining the maximum time that is permissive before these inhibitors lose their antiviral efficacy. We infected H9 cells at a high MOI (0.5) to synchronize all steps of viral replication. Three reference inhibitors, dextran sulfate (DS), AZT, and raltegravir (Ral), with known modes of action were used as controls for comparison with $\mathrm{M}_{5} 22$ and $\mathrm{M}_{5} 32$. Dextran sulfate (DS) is known to interfere with binding of the virus to the cell, the nucleoside analogue AZT inhibits the reverse transcription process, and raltegravir (Ral) is known to interfere with viral integration. Our data clearly indicated that addition of DS to the H9 cells before the viral infection was necessary, because its antiviral activity was lost when it was added after viral infection (Figure 5A). Conversely, the addition of AZT can be delayed up to $4 \mathrm{~h}$ after infection (Figure 5B), while raltegravir (Ral) only lost its activity when added more than $8 \mathrm{~h}$ after infection. IN inhibitors $\mathrm{M}_{5} 22$ and $\mathrm{M}_{5} 32$ produced a clearly different profile than the DS and AZT inhibitors (Figures $5 \mathrm{~A}$ and $5 \mathrm{~B}$ ), while sharing an identical profile with that of the Ral inhibitor (Figure 5C). These results strongly suggested that $\mathrm{M}_{5} 22$ and $\mathrm{M}_{5} 32$ did not inhibit viral entry and reverse transcription, but they interfered with the viral replication cycle at a point coinciding with the integration step.

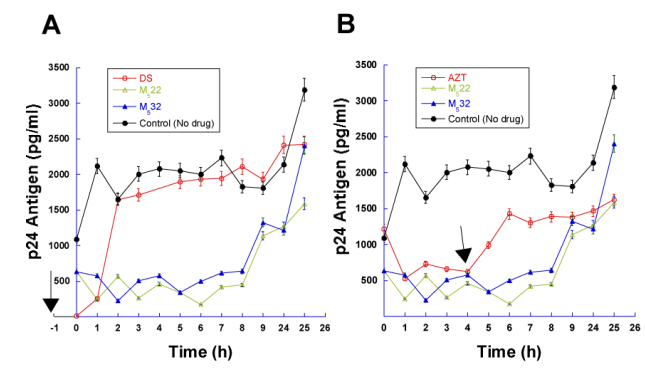

C

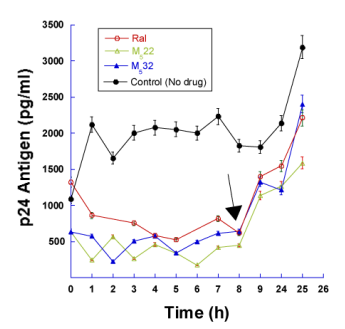

Figure 5: Effect of time of drug intervention on HIV replication cycle. H9 cells were infected with HIV-1 at a MOI of 0.5 and the test inhibitors were added at different times after infection (Panels $\mathrm{A}, \mathrm{B}$, and C). Viral p24 antigen values were determined at $72 \mathrm{~h}$ after infection for the means of three independent experiments and error bars represent standard deviations. The reference inhibitors DS (a viral binding inhibitor, Panel A); AZT (RT inhibitor, Panel B); and Ral (an IN inhibitor, Panel C) were used in parallel and compared with the $\mathrm{M}_{5} 22$ and $\mathrm{M}_{5} 32$ inhibitors versus the control. Arrows denote time points that the inhibitors lost their antiviral activity after this time.

\section{Search for emerging of HIV-1 mutants by the selection experiment in $\mathrm{H} 9$ cells}

To evaluate the propensity of these inhibitors to induce new resistance, we propagated $\mathrm{HIV}-1_{\mathrm{RTMF}}$ in $\mathrm{H} 9$ cells with the constant presence and absence of $\mathrm{M}_{5} 22$ and $\mathrm{M}_{5} 32$ inhibitors. These IN inhibitors were added at their $\mathrm{IC}_{50}$ values in the first passage of virus and the culture supernatant from each infection was used to infect new cells. We serially passed the virus with increasing concentrations of both inhibitors to 2-, 3-, and 4-times the $\mathrm{IC}_{50}$ values during the selection experiment. The antiviral activities of both inhibitors were determined against the selected strain in $\mathrm{H} 9$ cells for each passage. The results demonstrated that the selected virus was unable to replicate and no drug-resistant mutants developed during the passage of virus in the presence of $M_{5} 22$ and $M_{5} 32$ over 20 passages (160 days) versus the control virus without inhibitors, indicating that the HIV-1 $1_{\text {RTMF }}$ remained sensitive to both inhibitors even after 20 viral passages (Figure 6A). 

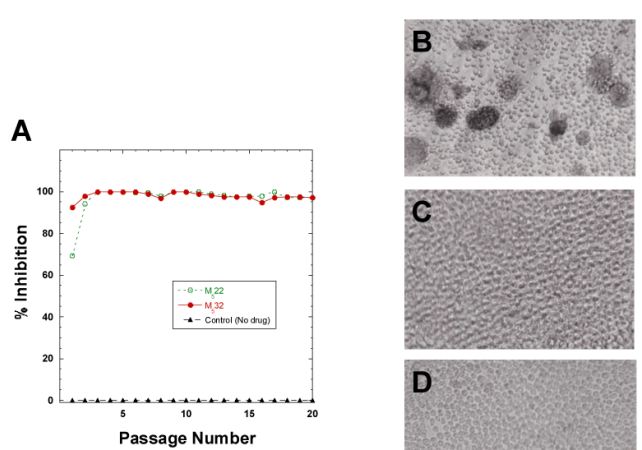

A

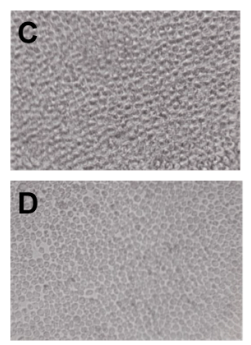

E

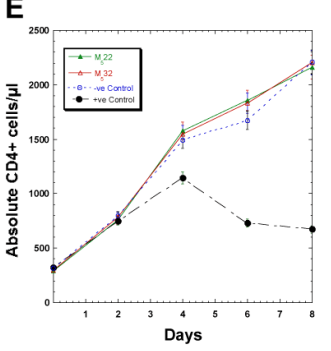

$\mathbf{F}$

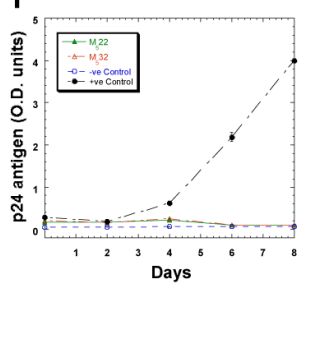

Figure 6: Selection of HIV-1 in H9 cells in the presence of $\mathrm{M}_{5} 22$ and $\mathrm{M}_{5} 32$ inhibitors, phase-contrast localization of $\mathrm{H} 9$ and effect of both inhibitors on absolute $\mathrm{CD} 4^{+} \mathrm{T}$-cell counts for the infected cells. Viral passages were performed for $\mathrm{H} 9$ cells in the presence of equal or increasing concentrations of both inhibitors. The antiviral activities were determined in the presence and absence of $\mathrm{M}_{5} 22$ and $\mathrm{M}_{5} 32$ against HIV-1 by using HIV-1 p24 antigen ELISA after 8 days for each passage and tested with both inhibitors through 20 passages (160 days) (Panel A). Panel B shows syncytia formation due to infection of H9 cells with HIV-1 as a positive control. Panel $\mathrm{C}$ shows the inhibition of HIV-1 replication in $\mathrm{H} 9$ cells by presence of the IN inhibitors $\left(\mathrm{M}_{5} 22, \mathrm{M}_{5} 32\right)$. H9 cells were infected, and then treated with the IN inhibitors, which prevented syncytia formation and protected the cells from the cytopathic effects. Panel D shows the uninfected $\mathrm{H} 9$ cells as a negative control to be compared with the infected cells, treated and non-treated ones with the IN inhibitors. Three groups of H9 cells were infected with HIV-1, where two groups were treated with the inhibitors $\left(M_{5} 22\right.$ and $\mathrm{M}_{5} 32$ ), the third group was not treated as a positive control, and the fourth group was uninfected cells as a negative control. The absolute $\mathrm{CD}^{+}{ }^{+} \mathrm{T}$-cell counts were calculated for all four groups (Panel E) and a comparison for quantitation of p24 antigen between the treated and non-treated groups of the infected cells with both inhibitors was evaluated versus the uninfected one (Panel F), where the values obtained from the means and standard deviations of three independent experiments.

\section{Protective effect of $M_{5} 22$ and $M_{5} 32$ on infected cells with HIV-1}

To examine the protection effect of the IN inhibitors $\left(\mathrm{M}_{5} 22\right.$ and $\mathrm{M}_{5} 32$ ) of $\mathrm{CD}^{+} \mathrm{T}$-cells, two groups of $\mathrm{H} 9$ cells were infected with HIV-1 $1_{\text {RTMF }}$ (AZT-resistant). The first group of the infected cells was in the absence of the IN inhibitors, and these cells formed syncytia.
Syncytia are giant multinucleated structures, clusters of many nuclei within a single cell membrane, and are a sign of HIV infection in cell cultures. They formed when HIV-infected cells make gp120 and carry it on their surface, fused with healthy cells bearing $\mathrm{CD} 4^{+}$molecules (Figure 6B). The second group of infected cells was treated with the IN inhibitors, where they inhibited HIV-1 replication, prevented syncytia formation and protected the cells from cytopathic effects (Figure 6C). The third group was uninfected $\mathrm{H} 9$ cells as a negative control to be compared with cells infected with HIV-1, treated and non-treated cells with the IN inhibitors. The treated cells with $M_{5} 22$ and $M_{5} 32$ were found to be morphologically identical to the uninfected cells (Figure 6D).

In addition, we performed more studies to test the protection effect of these IN inhibitors. A comparison of $\mathrm{CD} 4^{+} \mathrm{T}$-cell counts was done in four different groups using cytosphere assay. We infected two groups of H9 cells with HIV-1 $1_{\text {RTMF }}$ (AZT-resistant) and treated with the inhibitors $\left(\mathrm{M}_{5} 22\right.$ and $\left.\mathrm{M}_{5} 32\right)$, the third group was infected but not treated as a positive control, and the fourth group was uninfected cells as a negative control. The absolute $\mathrm{CD} 4^{+} \mathrm{T}$-cell counts were calculated for all four groups, where the number of $\mathrm{CD} 4^{+} \mathrm{T}$-count for the infected cells with HIV and treated with both inhibitors was very low at day zero then increased and back to the normal level as found for the uninfected cells after 8 days. Therefore, the groups treated with both IN inhibitors and the uninfected group showed an identical pattern and had higher $\mathrm{CD} 4^{+}$counts per $\mu$ l than the group of cells that was infected but not treated after 8 days (Figure 6E).

Furthermore, a comparison for quantitation of p24 antigen between the treated and non-treated groups of the infected cells with both inhibitors versus the uninfected cells was also calculated. The cells infected with HIV-1 and treated with $\mathrm{M}_{5} 22$ and $\mathrm{M}_{5} 32$ did not show any p 24 antigen and are identical to the uninfected cells as if they were not infected, whereas the cells infected but non-treated had very high p24 antigen after 8 days (Figure 6F).

\section{Discussion}

In the current study, we evaluated the antiviral efficacies of the IN inhibitors $\left(\mathrm{M}_{5} 22\right.$ and $\left.\mathrm{M}_{5} 32\right)$ against wild-type virus, different drugresistant HIV-1 strains and clinical isolate from infected patients. We found $M_{5} 22$ and $M_{5} 32$ are effective in stopping viral replication of many mutant strains that are resistant to RT, IN and PR drugs. By stopping the viral infection, $\mathrm{M}_{5} 22$ and $\mathrm{M}_{5} 32$ protected the infected cells from cytopathic effects caused by the virus yielding healthy $\mathrm{T}$ cells with high $\mathrm{CD}^{+}$cell counts identical to those of uninfected cells.

FDA approved raltegravir as an HIV-1 IN inhibitor in treatmentexperienced patients [26] and resistance to raltegravir in vivo was previously described [4]. This resistance due to the mutation combination of G140S/Q148H which is most relevant in vivo with the highest increase in resistance factor [27-29], and exhibits the greatest loss of drug susceptibility [30]. Therefore, the emergence of drugresistant HIV variants can attenuate the efficacy of antiretroviral treatment [31]. Our IN inhibitors $\mathrm{M}_{5} 22$ and $\mathrm{M}_{5} 32$ effectively suppressed the replication of resistant viruses containing G140S/ Q148H mutation that was isolated from patients in whom raltegravir treatment had been ineffective. Moreover, $\mathrm{M}_{5} 22$ and $\mathrm{M}_{5} 32$ have higher efficacies in inhibiting different drug-resistant HIV-1 strains and clinical isolate when compared to the scutellarin inhibitors [32], as well as having higher efficacies than the IN inhibitors of L-chicoric acid analogues for the drug-resistant clone [22]. Furthermore, our IN 
inhibitors showed higher activities against HIV-1 strains resistant to non-nucleoside RT (NNRTI), than the IN compounds L-708,906 and $\mathrm{V}-165$ [33]. In addition, $\mathrm{M}_{5} 22$ and $\mathrm{M}_{5} 32$ have high viral suppression against raltegravir-resistant and wild-type viruses showing a comparable pattern as displayed in their $\mathrm{IC}_{50}$ values. Overall, $\mathrm{M}_{5} 22$ and $\mathrm{M}_{5} 32$ inhibitors possess high potency against wild-type virus and different drug-resistant HIV-1 strains, particularly the clinically relevant integrase-resistant one of raltegravir.

The disintegration assay provided an effective tool for measurement of drug effects on IN deletion mutants [19]. We examined the interaction of $\mathrm{M}_{5} 22$ and $\mathrm{M}_{5} 32$ inhibitors by testing them with the catalytic core domain of HIV-1 IN and full-length IN. Both IN inhibitors showed higher efficacies against disintegration activity than those of other IN inhibitors; integric acid, equisetin [34], and $\alpha$ hydroxytropolone [35]. On comparison to the IN inhibitors, raltegravir and elvitegravir, $\mathrm{M}_{5} 22$ and $\mathrm{M}_{5} 32$ also showed high inhibition of disintegration activity, while both raltegravir and elvitegravir showed weak or no inhibition of this reaction [36]. Overall, we found that $M_{5} 22$ and $M_{5} 32$ inhibited disintegration activity by interacting with the catalytic core region and inhibit HIV-1 IN in a manner consistent with that of other IN inhibitors [37].

We have previously shown that $M_{5} 22$ and $M_{5} 32$ inhibited the activities of HIV-1 IN, 3'-processing and 3'-joining to the target DNA (strand transfer) [15]. Our current data also demonstrated that both $\mathrm{M}_{5} 22$ and $\mathrm{M}_{5} 32$ inhibited the disintegration activity with equivalent potency in the full-length IN and in its catalytic core domain. This is indicating that the catalytic core region is the target of interaction for both inhibitors and is responsible for the inhibition of HIV-1 IN and prevention of viral integration. Although $\mathrm{M}_{5} 22$ and $\mathrm{M}_{5} 32$ inhibitors bind to the catalytic core domain like some other FDA approved drugs of INSTIs, the potency of these inhibitors must come from their chemical structures; which play a potential role for binding interactions with HIV IN. Structural features of these two inhibitors that are crucial for the enzymatic activity are hydroxyl, aromatic ring and carboxylic acid moieties. To clarify potency of these two IN inhibitors, a recent reported study of molecular docking was conducted to determine the binding modes of $\mathrm{M}_{5} 22$ and $\mathrm{M}_{5} 32$ inhibitors within the catalytic core site of HIV-1 IN by using PFV IN model for WT (wild-type) and mutant variant, $\mathrm{S} 217 \mathrm{H}$ mutant (equivalent to G140S/Q148H HIV-1 IN). The docking calculations showed that the major key interactions for stabilization of $\mathrm{M}_{5} 22$ and $M_{5} 32$ binding are hydrogen bonding, metal-ligand, and $\pi-\pi$ stacking interactions with adenosine base A17 of the viral DNA, while these key interactions were not observed with raltegravir [38]. Another molecular docking study was conducted for $\mathrm{M}_{5} 22$ and $\mathrm{M}_{5} 32$ inhibitors using of HIV-1 IN [39] instead of PFV IN [38]. The docking results with HIV-1 IN indicated that the binding modes of $\mathrm{M}_{5} 22$ and $\mathrm{M}_{5} 32$ were similar to those of 5-CITEP inhibitor [39]. Moreover, the docking calculations showed that the carboxyl and hydroxyl groups on the side-chain of $\mathrm{M}_{5} 32$ are important chemical groups, which make $\mathrm{M}_{5} 32$ a tighter binder than $\mathrm{M}_{5} 22$ [39]. Overall, these two docking studies are supportive to our findings on the uniqueness of $\mathrm{M}_{5} 22$ and $\mathrm{M}_{5} 32$ as strong HIV-1 IN inhibitors.

The $\mathrm{CD} 4^{+}$cell count at initiation is the prognosis factor of HIV-1 in infected patients for a highly active antiretroviral therapy (HAART) [40]. In this case, viral load and CD4 cell counts serve as the two surrogate markers for monitoring of antiretroviral treatment (ART) responses and HIV disease progression where measurement of CD4 count is particularly useful before initiation of ART [41]. For these reasons, we have used the effect of $\mathrm{M}_{5} 22$ and $\mathrm{M}_{5} 32$ treatment on the AZT-resistant virus (HIV-1 $1_{\text {RTMF }}$ ) in culture as a mimic to HIVinfected patients. Similar to AIDS patients under an effective ART, although we found the $\mathrm{CD} 4^{+}$counts to be very low in non-treated and in infected cells during the early phase of the treatment, continuing $\mathrm{M}_{5} 22$ and $\mathrm{M}_{5} 32$ treatments not only blocked HIV-1 $1_{\mathrm{RTMF}}$ from further infection, they also brought numbers of $\mathrm{CD}^{+}$cells back to normal and identical to those of the uninfected cells after 8 days. This is an indication that these IN inhibitors are not toxic to the cells and protected the infected cells with drug-resistant virus from depletion of $\mathrm{CD}^{+} \mathrm{T}$-cells. All the presented data of the current study show the high inhibition activity of these IN inhibitors against drug-resistant strains and they did not build up any further drug resistance, at least in cell culture.

\section{Conclusion}

Our findings showed that the IN inhibitors $M_{5} 22$ and $M_{5} 32$ strongly suppressed the replication of different of HIV-1 strains (wildtype; different drug-resistant strains; clinical isolate from HIV-infected patients; and laboratory strains) grown in different cell types (H9, SupT1, and PBMC). In addition, they critically inhibited the viral replication of the clinically relevant raltegravir-resistant virus and did not induce drug resistance during the selection study. Moreover, disintegration studies support a model in which both inhibitors interacted with the catalytic core domain of HIV-1 IN, blocked its activity and inhibited viral replication. Time of intervention on HIV replication study also indicated that $\mathrm{M}_{5} 22$ and $\mathrm{M}_{5} 32$ interfered with the viral replication cycle at a time point coinciding with the integration step. Furthermore, these IN inhibitors protected the infected cells with HIV-1 from cytopathic effects and CD4 ${ }^{+}$T-cells depletion. This study has highlighted the application of $\mathrm{M}_{5} 22$ and $\mathrm{M}_{5} 32$ as candidate IN inhibitors for drug development against diverse HIV-1 strains, particularly for those drug-resistant HIV strains. These two selective IN inhibitors $\mathrm{M}_{5} 22$ and $\mathrm{M}_{5} 32$ hold the promise as a novel class of therapeutic drugs for AIDS patients based on their high potentials and in the absence of cytotoxicity.

\section{Acknowledgements}

This work was supported in part by grants from NIH (DE 12165) and Erimos Technologies, Houston, TX. The authors would like to thank Epidemiology Department, Bloomberg School of Public Health for using BSL-3 facility at Johns Hopkins Biological Repository to conduct our HIV-1 studies. We thank Dr. Akila Hadji for collecting the human blood and isolating PBMC. Also Dr. Robert Craigie, Laboratory of Molecular Biology, NIDDK, NIH, Bethesda, MD for providing the catalytic core domain (soluble mutant, F185K) of HIV-1 IN and Professor Zeger Debyser, Division of Molecular Medicine, Katholieke Universiteit Leuven, Flanders, Belgium for providing the raltegravir-resistant strain with mutations in HIV-1 IN and the wildtype virus of HIV-1. In addition, we thank Professor Karen Beemon and Dr. Tiffany Jackson, Biology Department at Johns Hopkins University for their comments on the manuscript.

\section{References}

1. Métifiot M, Marchand C, Maddali K, Pommier Y (2010) Resistance to integrase inhibitors. Viruses 2: 1347-1366.

2. Egbertson MS (2007) HIV integrase inhibitors: from diketoacids to heterocyclic templates: a history of HIV integrase medicinal chemistry at 
Merck West Point and Merck Rome (IRBM). Curr Top Med Chem 7: 1251-1272.

3. Summa V, Petrocchi A, Bonelli F, Crescenzi B, Donghi M, et al. (2008) Discovery of raltegravir, a potent, selective orally bioavailable HIVintegrase inhibitor for the treatment of HIV-AIDS infection. J Med Chem 51: 5843-5855.

4. Cooper DA, Steigbigel RT, Gatell JM, Rockstroh JK, Katlama C, et al. (2008) Subgroup and resistance analyses of raltegravir for resistant HIV-1 infection. N Engl J Med 359: 355-365.

5. Malet I, Delelis O, Valantin MA, Montes B, Soulie C, et al. (2008) Mutations associated with failure of raltegravir treatment affect integrase sensitivity to the inhibitor in vitro. Antimicrob Agents Chemother 52: 1351-1358.

6. Mouscadet JF, Delelis O, Marcelin AG, Tchertanov L (2010) Resistance to HIV-1 integrase inhibitors: A structural perspective. Drug Resist Updat 13: 139-150.

7. Hare S, Vos AM, Clayton RF, Thuring JW, Cummings MD, et al. (2010) Molecular mechanisms of retroviral integrase inhibition and the evolution of viral resistance. Proc Natl Acad Sci U S A 107: 20057-20062.

8. Rathbun RC, Lockhart SM, Miller MM, Liedtke MD (2014) Dolutegravir, a second-generation integrase inhibitor for the treatment of HIV-1 infection. Ann Pharmacother 48: 395-403.

9. Wensing AM, Calvez V, Günthard HF, Johnson VA, Paredes R, et al. (2014) 2014 Update of the drug resistance mutations in HIV-1. Top Antivir Med 22: 642-650.

10. Christ F, Voet A, Marchand A, Nicolet S, Desimmie BA, et al. (2010) Rational design of small-molecule inhibitors of the LEDGF/p75-integrase interaction and HIV replication. Nat Chem Biol 6: 442-448.

11. Kessl JJ, Jena N, Koh Y, Taskent-Sezgin H, Slaughter A, et al. (2012) Multimode, cooperative mechanism of action of allosteric HIV-1 integrase inhibitors. J Biol Chem 287: 16801-16811.

12. Tsiang M, Jones GS, Niedziela-Majka A, Kan E, Lansdon EB, et al. (2012) New class of HIV-1 integrase (IN) inhibitors with a dual mode of action. J Biol Chem 287: 21189-21203.

13. Christ F, Shaw S, Demeulemeester J, Desimmie BA, Marchand A, et al. (2012) Small-molecule inhibitors of the LEDGF/p75 binding site of integrase block HIV replication and modulate integrase multimerization. Antimicrob Agents Chemother 56: 4365-4374.

14. Demeulemeester J, Chaltin P, Marchand A, De Maeyer M, Debyser Z, et al. (2014) LEDGINs, non-catalytic site inhibitors of HIV-1 integrase: a patent review (2006 - 2014). Expert Opin Ther Pat 24: 609-632.

15. Abd-Elazem IS, Chen HS, Bates RB, Huang RC (2002) Isolation of two highly potent and non-toxic inhibitors of human immunodeficiency virus type 1 (HIV-1) integrase from Salvia miltiorrhiza. Antiviral Res 55: 91-106.

16. Lewinski MK, Bushman FD (2005) Retroviral DNA integration-mechanism and consequences. Adv Genet 55: 147-181.

17. LaFemina RL, Schneider CL, Robbins HL, Callahan PL, LeGrow K, et al. (1992) Requirement of active human immunodeficiency virus type 1 integrase enzyme for productive infection of human T-lymphoid cells. J Virol 66: 7414-7419.

18. Goldgur Y, Craigie R, Cohen GH, Fujiwara T, Yoshinaga T, et al. (1999) Structure of the HIV-1 integrase catalytic domain complexed with an inhibitor: a platform for antiviral drug design. Proc Natl Acad Sci U S A 96: 13040-13043.

19. Chow SA, Vincent KA, Ellison V, Brown PO (1992) Reversal of integration and DNA splicing mediated by integrase of human immunodeficiency virus. Science 255: 723-726.

20. Chow SA (1997) In vitro assays for activities of retroviral integrase. Methods 12: 306-317.

21. di Marzo Veronese F, Sarngadharan MG, Rahman R, Markham PD, Popovic M, et al. (1985) Monoclonal antibodies specific for p24, the major core protein of human T-cell leukemia virus type III. Proc Natl Acad Sci U S A 82: 5199-5202.
22. King PJ, Ma G, Miao W, Jia Q, McDougall BR, et al. (1999) Structureactivity relationships: analogues of the dicaffeoylquinic and dicaffeoyltartaric acids as potent inhibitors of human immunodeficiency virus type 1 integrase and replication. J Med Chem 42: 497-509.

23. De Clercq E, Yamamoto N, Pauwels R, Baba M, Schols D, et al. (1992) Potent and selective inhibition of human immunodeficiency virus (HIV)-1 and HIV-2 replication by a class of bicyclams interacting with a viral uncoating event. Proc Natl Acad Sci U S A 89: 5286-5290.

24. Larder BA, Coates KE, Kemp SD (1991) Zidovudine-resistant human immunodeficiency virus selected by passage in cell culture. J Virol 65: 5232-5236.

25. Carella AV, Moss MW, Provost V, Quinn TC (1995) A manual bead assay for the determination of absolute CD4+ and CD8+ lymphocyte counts in human immunodeficiency virus-infected individuals. Clin Diagn Lab Immunol 2: 623-625.

26. Temesgen Z, Siraj DS (2008) Raltegravir: first in class HIV integrase inhibitor. Ther Clin Risk Manag 4: 493-500.

27. Fransen S, Gupta S, Danovich R, Hazuda D, Miller M, et al. (2009) Loss of raltegravir susceptibility by human immunodeficiency virus type 1 is conferred via multiple nonoverlapping genetic pathways. J Virol 83: $11440-11446$.

28. Fransen S, Karmochkine M, Huang W, Weiss L, Petropoulos CJ, et al. (2009) Longitudinal analysis of raltegravir susceptibility and integrase replication capacity of human immunodeficiency virus type 1 during virologic failure. Antimicrob Agents Chemother 53: 4522-4524.

29. Quercia R, Dam E, Perez-Bercoff D, Clavel F (2009) Selective-advantage profile of human immunodeficiency virus type 1 integrase mutants explains in vivo evolution of raltegravir resistance genotypes. J Virol 83: 10245-10249.

30. Johnson VA, Brun-Vezinet F, Clotet B, Günthard HF, Kuritzkes DR, et al. (2008) Update of the drug resistance mutations in HIV-1: Spring 2008. Top HIV Med 16: 62-68.

31. Shimura K, Kodama E, Sakagami Y, Matsuzaki Y, Watanabe W, et al. (2008) Broad antiretroviral activity and resistance profile of the novel human immunodeficiency virus integrase inhibitor elvitegravir (JTK-303/GS-9137). J Virol 82: 764-774.

32. Zhang GH, Wang Q, Chen JJ, Zhang XM, Tam SC, et al. (2005) The antiHIV-1 effect of scutellarin. Biochem Biophys Res Commun 334: 812-816.

33. Pannecouque C, Pluymers W, Van Maele B, Tetz V, Cherepanov P, et al. (2002) New class of HIV integrase inhibitors that block viral replication in cell culture. Curr Biol 12: 1169-1177.

34. Hazuda D, Blau CU, Felock P, Hastings J, Pramanik B, et al. (1999) Isolation and characterization of novel human immunodeficiency virus integrase inhibitors from fungal metabolites. Antivir Chem Chemother 10: 63-70.

35. Semenova EA, Johnson AA, Marchand C, Davis DA, Yarchoan R, et al. (2006) Preferential inhibition of the magnesium-dependent strand transfer reaction of HIV-1 integrase by alpha-hydroxytropolones. Mol Pharmacol 69: 1454-1460.

36. Marinello J, Marchand C, Mott BT, Bain A, Thomas CJ, et al. (2008) Comparison of raltegravir and elvitegravir on HIV-1 integrase catalytic reactions and on a series of drug-resistant integrase mutants. Biochemistry 47: 9345-9354.

37. Neamati N, Hong H, Sunder S, Milne GW, Pommier Y (1997) Potent inhibitors of human immunodeficiency virus type 1 integrase: identification of a novel four-point pharmacophore and tetracyclines as novel inhibitors. Mol Pharmacol 52: 1041-1055.

38. Nunthaboot N, Lugsanangarm K, Kokpol S, Abd-Elazem IS (2013) Binding mode prediction of biologically active compounds from plant Salvia Miltiorrhiza as integrase inhibitor. Bioinformation 9: 426-431.

39. Zhu HM, Chen WZ, Wang CX (2004) Binding modes of two highly potent and nontoxic inhibitors of HIV-1 integrase. Conf Proc IEEE Eng Med Biol Soc 4: 3003-3006.

40. Egger M, May M, Chêne G, Phillips AN, Ledergerber B, et al. (2002) Prognosis of HIV-1-infected patients starting highly active antiretroviral 
Citation: Abd-Elazem IS, Huang RCC (2014) Inhibition of the Replication of Clinical Drug-Resistant HIV-1 Strains by Small Molecule Integrase Inhibitors $M_{5} 22$ and $M_{5}$ 32. J AIDS Clin Res 5: 378. doi:10.4172/2155-6113.1000378

Page 9 of 9

therapy: a collaborative analysis of prospective studies. Lancet 360 119-129.
41. Department of Health and Human Services (2014) Guidelines for the use of antiretroviral agents in HIV-1-infected adults and adolescents. 